\title{
As contribuições de um curso de Modelagem Matemática para a formação e atuação de professores que ensinam Matemática
}

\author{
The contributions of a Mathematical Modeling course to the training and \\ performance of teachers who teach Mathematics
}

\author{
Edyenis Rodrigues Frango \\ Marco Aurélio Kistemann Junior
} \begin{abstract}
questionários aplicados e das observações e interações com os participantes durante a formação realizada. Esses apontamentos evidenciam a carência dos cursos de formação de professores em relação à Modelagem Matemática. Como principal resultado da pesquisa, apresenta-se um Produto Educacional voltado para a formação inicial e continuada de professores de Matemática.
\end{abstract}

Resumo: Este artigo apresenta os resultados de uma pesquisa realizada no Mestrado Profissional em Educação Matemática da Universidade Federal de Juiz de Fora (UFJF) que investigou a formação de professores que ensinam Matemática com a temática da Modelagem Matemática. Esta pesquisa, realizada em três fases com professores - pesquisa piloto, pesquisa pós-piloto e desenvolvimento do produto educacional - buscou compreender a relação desses professores com a Modelagem, tanto na sua formação quanto na sua prática docente. A cada fase da pesquisa foi possível perceber os anseios dos professores que ensinam Matemática por meio de

Palavras-chave: Modelagem Matemática. Formação de Professores. Produto Educacional.

Abstract: This article presents the results of a research conducted in the Professional Master's Degree in Mathematics Education of the Federal University of Juiz de For a (UFJF) that investigated the training of teachers who teach Mathematics with the theme of Mathematical Modeling. This research, carried out in three phases with teachers pilot research, post-pilot research and development of the educational product - sought to understand the relationship of these teachers with modeling, both in their training and in their teaching practice. At each stage of the research it was possible to perceive the desires of teachers who teach mathematics through applied questionnaires and observations and interactions with participants during the training performed. These notes show the lack of teacher training courses in relation to Mathematical Modeling. As the main result of the research, an Educational Product focused on the initial and continued training of mathematics teachers is presented.

Keywords: Mathematical Modeling. Teacher Training. Educational Product.

\section{Introdução}

Este artigo tem como objetivo apresentar a nossa pesquisa de mestrado profissional
Edyenis Rodrigues Frango Mestre em Educação Matemática. Professora do Instituto do Noroeste Fluminense de Educação Superior da Universidade Federal Fluminense (INFES/UFF). Rio de Janeiro,

(iD) orcid.org/0000-0001-7865-1135 $凶$ edyenisfrango@gmail.com

Marco Aurélio Kistemann Junior Doutor em Educação Matemática. Professor do Programa de Pós-Graduação em Gestão e Avaliação em Educação Pública e do Programa de Pós-Graduação em Educação Matemática da Universidade Federal de Juiz de Fora (UFJF). Minas Gerais, Brasil. (iD) orcid.org/0000-0002-8970-3954 凹 kistemann1972@gmail.com

Recebido em 01/05/2020 Aceito em 15/06/2020 Publicado em 13/07/2020 
intitulada de As contribuições de um curso de formação em Modelagem Matemática para 0 desenvolvimento de um guia formativo na perspectiva dos professores de Matemática participantes (FRANGO, 2019). A palavra nossa é importante, pois a pesquisa possibilitou uma atuação conjunta e colaborativa, orientador-orientanda, nas escolhas teóricas, metodológicas e epistemológicas ao longo do percurso tanto da pesquisa piloto, quanto da pesquisa de campo (segunda etapa), bem como na elaboração do produto educacional resultante da pesquisa.

Como é o primeiro artigo produzido sobre a pesquisa com a temática da Modelagem Matemática, escolhemos dar uma visão panorâmica da investigação como um todo, bem como enfatizamos que concebemos a Modelagem Matemática como uma metodologia importante para a aprendizagem dos conteúdos matemáticos na sala de aula.

Nesse contexto, a pesquisa foi desenvolvida no Mestrado Profissional em Educação Matemática (UFJF), por integrantes do grupo Pesquisa de Ponta (UFJF), buscando responder a seguinte pergunta diretriz: O que deve oferecer um curso de Modelagem Matemática no contexto da Educação Matemática de forma a influenciar positivamente as práticas docentes dos professores envolvidos?. Salientamos que o termo Modelagem é uma forma mais sucinta de escrever Modelagem Matemática e o utilizaremos ao longo do artigo, pois já é um termo consagrado na literatura da Educação Matemática.

Assim, o objetivo geral da pesquisa foi observar, descrever e compreender como professores que ensinam Matemática concebem Modelagem em suas futuras práticas de ensino. Buscamos identificar as relações com as experiências e concepções docentes de Matemática e Ensino, no contexto da disciplina de Modelagem Matemática do Programa de Pós-Graduação em Educação Matemática da Universidade Federal de Juiz de Fora (UFJF).

O objetivo específico de pesquisa era produzir um produto educacional que atendesse aos anseios da comunidade acadêmica e auxiliasse a formação de professores no que diz respeito à Modelagem. Dessa forma, elaboramos um produto que contribuísse para a prática do futuro professor de Matemática que pretenda utilizar essa metodologia em seu cotidiano. Assim, esta pesquisa gerou um produto educacional denominado Modelagem Matemática - um guia de formação, que busca orientar e convidar os professores a desenvolverem a Modelagem Matemática em suas salas de aula.

Inicialmente, foi realizada uma Pesquisa Piloto, na qual utilizamos questionários com a intenção de conhecer a relação dos professores que ensinam Matemática com a Modelagem 
Matemática, tanto em sua formação inicial quanto em sua formação continuada, buscando entender como estes professores atuavam em suas práticas pedagógicas. As respostas a esse questionário nos possibilitaram estruturar a segunda fase desta pesquisa, denominada de Pesquisa de Campo. Nessa segunda, etapa produzimos dados que nos possibilitaram desenvolver um produto educacional que consistiu em um manual formativo em Modelagem Matemática que detalharemos mais à frente.

Nossa experiência, de ambos os autores deste artigo, no Programa Institucional de Bolsas de Iniciação à Docência (PIBID), como bolsista no caso da primeira autora, bem como coordenador no caso do segundo autor, também influenciaram na escolha do tema da Modelagem. Percebemos que a licenciatura da UFJF, na qual atua o segundo autor, a Modelagem ainda é muito pouco abordada na formação inicial de professores que ensinam Matemática e o estudo piloto nos revelou esse fato.

No caso específico da Licenciatura em Matemática da UFJF, o estudante só terá um contato formal disciplinar explícito e curricular com Modelagem na pós-graduação, com aprofundamento em leituras de pesquisas e aproximação das linhas de ação dessas metodologias. Diante disso, conjecturamos que muitos professores podem estar atuando, após a sua licenciatura em Matemática, desconhecendo a Modelagem como uma metodologia alternativa que promova ambientes de aprendizagem e investigação.

A Base Nacional Comum Curricular (BNCC) já traz orientações quanto à utilização de metodologias alternativas de ensino e de aprendizagem e de novas tecnologias disponíveis que podem auxiliar as práticas docentes (BRASIL, 2017) de modo que o professor seja um mediador das ações investigativas dos estudantes. A ênfase em metodologias de ensino de Matemática que reifiquem a centralidade do professor como único detentor do conhecimento, e em decorrência disso, coloca os estudantes como meros coadjuvantes do processo, tem gerado um afastamento e desencantamento desses estudantes com a Matemática.

Para Machado (2017), esse desencantamento com a Matemática vem ocorrendo, mesmo o estudante tendo ciência de que esta disciplina pode prover-lhe ferramentas para resolução de vários problemas em seu cotidiano. Assim, há várias propostas para superar este crescente desencantamento com a Matemática como apontado pelo autor, como a Modelagem. Exemplos disso são projetos mediados por um professor de Matemática, que orienta seus estudantes a investigarem temas, modelá-los, apresentar seus resultados em seminários, ou seja, um professor 
que busca transgredir o status quo ou atuar de forma insubordinada e criativa, conforme nos esclarece Lopes e D’Ambrósio (2016).

Diante do exposto, destacamos que o interesse inicial em realizar a pesquisa, além da nossa percepção do desencantamento e do desinteresse de muitos estudantes, deveu-se também à pesquisa de Barbosa (2001). A pesquisa desse educador matemático consistiu em analisar as concepções dos licenciandos em Matemática do campus Rio Claro da Universidade Estadual Paulista sobre o que entendiam por Matemática, Educação Matemática e Modelagem Matemática, e se essas concepções se modificaram após os participantes, de sua pesquisa, se envolverem em um programa de formação em Modelagem. Assim, passados 16 anos da defesa e publicação de sua tese, buscamos investigar em outro contexto e com outros professores, o perfil do professor que ensina Matemática, no que diz respeito à presença — ou ausência — da Modelagem na sua formação profissional e, consequentemente, na sua prática docente.

Desse modo, nossa opção de pesquisa em Modelagem Matemática justifica-se e inspirase nas inquietações de Barbosa (2001). Como defende este autor, a Modelagem Matemática, no contexto da Educação Matemática, constitui-se um ambiente de aprendizagem que propicia 0 desenvolvimento dos conteúdos matemáticos numa perspectiva sócio-crítica.

Nesse contexto, delimitamos o tema de pesquisa, a investigar qual o lugar da Modelagem Matemática na formação do professor que ensina Matemática e que lugar passa a ocupar na futura prática do professor que toma contato com ela, levando-se em conta suas experiências acerca do que se entende por Matemática, Modelagem Matemática e ensino de Matemática.

A seguir, detalharemos nossas opções e percursos metodológicos que nos permitiram realizar escolhas, por meio de um estudo piloto, escolhas que definiram os instrumentos metodológicos e o design estrutural do produto educacional. Por fim, é importante dizer que a realização desta pesquisa estava intimamente relacionada ao ambiente em que ocorre o fenômeno sobre o qual se debruça a formação de professores, e aos sujeitos dessa ação: os professores. 0 fato da pesquisa ter sido direcionada aos professores, considerando toda a complexidade que envolve uma formação efetiva e satisfatória e o seu envolvimento com esta formação, bem como o ambiente na qual se desenvolve, fez-nos optar por uma abordagem qualitativa (D'AMBROSIO, 2012). 


\section{Fundamentação teórica e revisão de literatura}

Em nossa pesquisa buscamos fundamentar-nos em pesquisas já realizadas na sala de aula de Matemática da Educação Básica, incluindo pesquisas que revelam indícios da atuação do professor de Matemática em cenários para investigação.

Dessa forma, inicialmente, pesquisamos os trabalhos e investigações realizadas e expostas no Quadro 1, a seguir:

Quadro 1: Áreas de pesquisa e autores consultados

\begin{tabular}{|c|c|}
\hline Área de Pesquisa & Autores \\
\hline Formação de Professores de Matemática & $\begin{array}{c}\text { Dario Fiorentini e Sérgio Lorenzato } \\
(2006)\end{array}$ \\
\hline $\begin{array}{c}\text { Formação de Professores } \\
\text { Metodologias de Ensino e Práticas } \\
\text { Pedagógicas }\end{array}$ & $\begin{array}{c}\text { Antonio Nóvoa (2009) } \\
\text { Maurice Tardif (2010) }\end{array}$ \\
\hline $\begin{array}{c}\text { Diálogo e Aprendizagem em Matemática } \\
\text { Modelagem Matemática }\end{array}$ & Helle Alrø e Ole Skovsmose (2010) \\
\hline $\begin{array}{c}\text { Jonei Barbosa (2001) } \\
\text { Andreia Oliveira (2010) }\end{array}$ \\
\hline Responsável & Beatriz D'Ambrósio e Celi Espasandin \\
Lopes (2016)
\end{tabular}

Fonte: Autores da Pesquisa

As pesquisas desses referenciais teóricos, apresentados no Quadro 1, nos auxiliaram a enriquecer nosso arcabouço epistemológico como pesquisadores, possibilitando-nos ampliar nossos conhecimentos sobre as teorizações dos autores do Quadro 1. Auxiliaram, sobretudo, a estruturarmos o percurso metodológico da pesquisa, definindo etapas, instrumentos metodológicos para a produção e análise dos dados, bem como auxiliaram a estruturar uma proposta de curso de formação em Modelagem Matemática para professores que ensinam Matemática, no contexto do estudo pós-piloto da pesquisa. Como resultado, obtivemos o produto educacional que será detalhado mais à frente e que agregou as preciosas contribuições dos pesquisadores apresentados no Quadro 1.

Destacamos, também, a relevância da atuação e das pesquisas do Grupo de Trabalho de Modelagem Matemática, o GT-10 da Sociedade Brasileira de Educação Matemática (SBEM), cuja missão é favorecer a discussão relativa à Modelagem Matemática no âmbito da Educação 
Matemática com a colaboração dos pesquisadores brasileiros. As pesquisas apresentadas e discutidas nos eventos em que o GT-10 participa também fizeram parte de nossos estudos e auxiliaram no design e delineamento de ações que culminaram na elaboração do nosso produto educacional buscando dar a este produto a organicidade para práticas de Modelagem Matemática que convidassem o professor mediador e os estudantes a investigarem temas inerentes ao seu contexto.

De acordo com Machado (2017), devido ao alto grau de abstração inerente à Matemática, principalmente no tocante à aprendizagem de certos temas, nos variados níveis educacionais, muitos dos sujeitos que se envolvem - estudantes e professores - com a Matemática criam rejeição ou apresentam dificuldades de entendimento e de compartilhamento das ideias essenciais a essa área do conhecimento.

O resultado, no entendimento de Machado (2017), são práticas de ensino arcaicas e dissonantes da realidade dos estudantes, bem como uma aprendizagem discente artificial e frágil, em geral obtida a partir de tentativas de transmissão de conhecimento ou regras e algoritmos. Em suma, a maioria dos estudantes, diante desse quadro, tem rejeitado e se desmotivado, com 0 tempo, de seguir as propostas de seu professor.

Para Machado (2017), ocorre um desencantamento com a Matemática, mesmo o estudante tendo ciência de que esta disciplina pode prover-lhe de ferramentas para resolução de vários problemas em seu cotidiano. Ao longo de nossa pesquisa, em espaços de diálogos com os participantes, em vários momentos, verificamos que o desencantamento não só pode ocorrer no corpo discente, mas pode atingir o corpo docente na medida em que a desvalorização da profissão de professor no Brasil tem sido crescente ao longo dos últimos trinta anos.

Em suma, os futuros professores podem estar atuando já durante a sua licenciatura em Matemática, mas ao se formarem e se afastarem do meio acadêmico, acabam desconhecendo novas propostas de ensino e de aprendizagem que promovam ambientes de aprendizagem envolvendo a Modelagem. A esse respeito, dentre as muitas propostas metodológicas existentes, a Base Nacional Comum Curricular (BNCC) aponta a Modelagem Matemática como alternativa ao desenvolvimento do estudante crítico e capaz de compreender e aplicar a Matemática em situações do seu cotidiano (BRASIL, 2017).

Existem várias propostas para superar tal desencantamento com a Matemática, entre as quais, destacamos a eleita para nossa pesquisa: a Modelagem Matemática. Recordamos que a 
Modelagem Matemática tem suas raízes na Matemática Aplicada e guarda algumas reminiscências desse lócus original, mais em alguns autores e menos em outros. Rodney Bassanezi tem suas ações fortemente apoiadas na Matemática Aplicada. Assim, o termo Modelagem tem sido constantemente relacionado à Matemática Aplicada. Com base nessa relação, Bassanezi (2004) a define como

\footnotetext{
um processo dinâmico utilizado para a obtenção e validação de modelos matemáticos. É uma forma de abstração e generalização com a finalidade de previsão de tendências. A modelagem consiste, essencialmente, na arte de transformar situações da realidade em problemas matemáticos cujas soluções devem ser interpretadas na linguagem usual. (p. 24)
}

Contudo, quando se fala de Modelagem Matemática na Educação Matemática sente-se alguma resistência por parte dos professores em implementá-la em suas salas de aula. Essa resistência pode ser causada por vários fatores, como o desconhecimento do professor quanto ao que seja Modelagem; a dificuldade de docentes e discentes frente a alguns conteúdos; a relação da carga horária com o cumprimento do currículo; como se dá o processo avaliativo frente a essa proposta de ensino com Modelagem; e ainda outras (SILVEIRA e CALDEIRA, 2012).

Em decorrência dessa resistência em relação à Modelagem, busca-se, a partir de pesquisas e análise da literatura, apresentar a Modelagem Matemática no contexto da Educação Matemática como tendência desta, e descrever quem e onde se pesquisa nesta área, bem como analisar sua evolução no que diz respeito a pesquisas desenvolvidas até então.

Diante do exposto, destacamos que em vários momentos houve a necessidade de se conhecer o que estava sendo produzido pela comunidade acadêmica, buscando por meio de levantamentos bibliográficos constituirmos a nossa revisão de literatura. Assim, foram realizados levantamentos bibliográficos direcionados às produções em Modelagem Matemática, tanto abrangendo temas gerais quanto temas específicos (SILVEIRA, 2007; ARAÚJO, 2010; BIEMBENGUT, 2009), assim como sua relação com o currículo, sua aplicabilidade nas salas de aula de Matemática dos diversos níveis de escolaridade, e na formação de professores.

Destacamos, a seguir, os pesquisadores que realizaram investigações que abordaram a formação do professor de Matemática e estruturação de ações envolvendo a Modelagem Matemática, uso de tecnologias e propostas alternativas. A justificativa de explicitarmos esses pesquisadores não é meramente para citá-los, mas, sobrtudo para deixar claro que suas pesquisas foram utilizadas tanto por nós, quanto pelos participantes do estudo pós-piloto na disciplina 
ministrada e que resultou no produto educacional. São alguns dos pesquisadores que têm nos inspirado e estabelecido a excelência das pesquisa em Modelagem no Brasil e no exterior.

Assim, estas pesquisas nos inspiraram pelo esforço de se problematizar ambientes para aprendizagem a partir de ações de Modelagem Matemática considerando diferentes perspectivas dos autores: Burak (1992); Barbosa (2001, 2007); Biembengut (2004; 2009); Rosa (2005); Silveira (2007); Araújo (2012); Malheiros (2012); Assis (2013); Canedo Jr. (2014); Tambarussi (2015); Oliveira (2016); Mutti (2016); Bassanezi (2004); Tortola (2016); Borba, Villareal e Soares (2016); Rosa e Orey (2017); e Silva e Borssoi (2017).

O critério para elencarmos tais pesquisadores reside no fato de que suas investigações abordam a Modelagem como metodologia ou procedimento investigativo em sala de aula, em diversos contextos sociais e níveis de ensino. Reiteramos que as pesquisas realizadas por esses educadores constitum-se também como referências não só no contexto nacional, mas estabelecem-se como estudos imprescindíveis para a formação de professores inicial e continuada, bem como pode auxiliar na estruturação de práticas de Modelagem na sala de aula de Matemática.

Destarte, concebemos a Modelagem como uma metodologia de ensino e de aprendizagem que pode oportunizar aos educadores um ambiente de aprendizagem. Nesse ambiente, os estudantes mediados pelo professor podem investigar temáticas alinhadas com seu entorno cultural e social buscando utilizar os conhecimentos matemáticos e científicos escolares para solucionar problemas. Inspirados também em Skovsmose (2000) e Canedo Jr. (2014), buscamos em nossa prática, a partir do guia elaborado nessa pesquisa, promover cenários para investigação com temáticas sugeridas e trazidas pelos estudantes para que as ações de Modelagem ocorram na sala de aula de escolas públicas e no contexto do ensino superior.

De acordo com Skovsmose (2000), um cenário para investigação constitui-se num ambiente que pode dar suporte a um trabalho de investigação, desenvolvendo ações de investigação, questionamentos, formulação de conjecturas que promovam a criticidade dos sujeitos envolvidos. Optamos por estabelecer cenários para investigação em contraposição a práticas que reificam práticas embasadas no paradigma do exercício. É nesse sentido que concordamos com Skovsmose (2000) quando este educador matemático enfatiza que 
matemática e engajar os alunos activamente em seus processos de aprendizagem. Mover-se da referência à matemática pura para a referência à vida real pode resultar em reflexões sobre a matemática e suas aplicações. Minha expectativa é que caminhar entre os diferentes ambientes de aprendizagem pode ser uma forma de engajar os alunos em acção e reflexão e, dessa maneira, dar à educação matemática uma dimensão crítica. (p. 66)

Em suma, como defende Skovsmose (2001), a educação tem papel de provocar a criticidade dos indivíduos, de tal forma a levá-los a pensar cultural, política e socialmente, fazendo com que os sujeitos envolvidos no processo educacional ajam e reajam conscientes de seus papéis como cidadãos frente aos acontecimentos. É em sintonia com as ideias de Ole Skovsmose que nos inspiramos em muitos momentos desafiadores da pesquisa realizada.

\title{
3 Percursos metodológicos da pesquisa
}

No início da nossa pesquisa, de abordagem qualitativa, não sabíamos ainda que percursos metodológicos ou instrumentos de pesquisa se adequariam aos seus objetivos. Após a realização de um estudo piloto (Estudo de Caso) e a análise dos dados produzidos neste estudo, decisões foram tomadas nesse sentido, inclusive já atentando para como seria o design e a funcionalidade do produto educacional.

No tocante à pesquisa com abordagem qualitativa, Goldenberg (1997) enfatiza que

\begin{abstract}
a pesquisa qualitativa não se preocupa com representatividade numérica, mas sim com o aprofundamento da compreensão de um grupo social, de uma organização etc. Os pesquisadores que adotam a abordagem qualitativa se opõem ao pressuposto que defende um modelo único de pesquisa para todas as ciências, já que as ciências sociais têm sua especificidade, o que pressupõe uma metodologia própria. Assim, os pesquisadores qualitativos recusam o modelo positivista aplicado ao estudo da vida social, uma vez que o pesquisador não pode fazer julgamentos nem permitir que seus preconceitos e crenças contaminem a pesquisa. (p. 27)
\end{abstract}

Assim, a seguir, detalharemos as duas etapas da pesquisa realizada, o Estudo Piloto e 0 Estudo Pós-Piloto. Essas etapas nos possibilitaram refinar e fazer escolhas metodológicas que foram imprescindíveis para a qualidade de uma pesquisa qualitativa no sentido apontado por Minayo (2001). Esta pesquisadora enfatiza, ainda, que a pesquisa com abordagem qualitativa trabalha com o universo de significados, motivos, aspirações, crenças, valores e atitudes, correspondendo a um espaço mais profundo das relações, dos processos e dos fenômenos que não podem ser reduzidos à operacionalização de variáveis. 


\subsection{Detalhando o contexto do Estudo Piloto}

Para a realização do estudo piloto, considerado um Estudo de Caso, de acordo com Yin (2001), foram utilizados, com os participantes, professores que ensinam Matemática, questionários nos moldes de Fiorentini e Lorenzato (2006). Já na etapa pós-piloto, a pesquisa é considerada como um estudo de caso por Yin (2001) e André (1984) e pesquisa-ação (THIOLLENT, 2005). Como a pesquisa foi realizada numa disciplina do mestrado profissional, com a participação de outros professores, foram utilizados instrumentos metodológicos para a produção de dados qualitativos, como questionário (FIORENTINI e LORENZATO, 2006), observação participante (GERHARDT e SILVEIRA, 2009) e análise documental (FONSECA, 2002).

Assim, em dois momentos durante esta pesquisa utilizamos questionários como opção metodológica para a produção de dados. O primeiro momento foi na fase inicial desta investigação, quando foi realizada a pesquisa piloto, para conhecer o perfil dos professores, quanto à sua formação em Modelagem.

$\mathrm{Na}$ etapa pós-piloto da pesquisa o questionário foi utilizado como forma de avaliar 0 trabalho desenvolvido ao longo da disciplina ministrada com os sujeitos que denominamos de professores-colaboradores desta pesquisa-ação. A seguir, detalharemos, metodologicamente, as duas etapas realizadas na pesquisa, o estudo piloto e a investigação pós-piloto, ambas as etapas que nos possibilitaram produzir dados qualitativos para responder nossa pergunta diretriz e guiar nossas ações para a estruturação do produto educacional.

No estudo piloto realizado, caracterizado como um estudo de caso (YIN, 2001), esta pesquisa buscou a compreensão a respeito do que pode estar afastando a Modelagem da prática dos professores, a partir dos motivos apontados pelos participantes da pesquisa piloto - dados estes que não são possíveis é possível quantificar - o que faz com que este trabalho assuma características qualitativas.

Como relatado anteriormente, ao realizarmos o estudo piloto, ainda não havíamos definido o design do produto educacional, porém sabíamos que a estrutura do produto deveria estar voltada para a formação do professor com relação à Modelagem Matemática. Em nosso entendimento e experiência, era preciso, então, conhecer qual a relação do professor de Matemática com a Modelagem, para que essa estrutura e o design final do produto possibilitasse aos professores desenvolver ambientes de modelagem em suas práticas escolares. 
Assim, o objetivo geral do estudo piloto foi traçar o perfil do professor que ensina Matemática, buscando conhecer suas experiências e concepções com relação à Modelagem Matemática e, assim, pensar como auxiliar o professor na problematização de cenários que promovam, de fato, a aprendizagem da Matemática por meio da Modelagem. Os objetivos específicos do estudo piloto foram: (i) descrever e compreender as concepções de professores que ensinam Matemática em relação à Matemática e seu ensino; e (ii) descrever, interpretar e discutir as experiências pessoais com a Matemática e, particularmente, com a Modelagem, relatadas por estes sujeitos.

Os vinte e quatro sujeitos da pesquisa piloto eram professores licenciados em Matemática, bacharéis em Matemática e pedagogos que ensinam Matemática nos vários níveis de ensino, e com diferentes tempos de exercício da profissão docente. Esses sujeitos do estudo piloto foram definidos levando-se em consideração o perfil de profissionais que atuam nas salas de aula de Matemática não se limitando aos licenciados em Matemática, mas também profissionais com outra formação, habilitados para ensinar Matemática.

Por meio de um formulário eletrônico do Google, o questionário foi enviado para professores, por e-mail, buscando a preservação da identidade de todos os participantes, permitindo, assim, que tivessem maior liberdade de expressar suas opiniões sobre o tema investigado. Os dados produzidos e analisados a partir desse questionário enviado a cada professor participante do estudo piloto buscou inquerir sobre os currículos e as ementas disciplinares dos cursos - principalmente das Licenciaturas em Matemática -, nos quais os participantes se graduaram, e avaliar a presença/ausência da Modelagem Matemática nele(s).

O questionário elaborado para o estudo piloto foi constituído por doze questões, divididas em três categorias. Nas questões 1 e 2, o respondente foi inquirido sobre sua formação acadêmica; nas questões 3 a 5, sobre sua atuação profissional; nas questões 6 a 12, buscamos conhecer o seu entendimento do que seja Matemática, Educação Matemática, Modelagem Matemática, de como os sujeitos percebem o ensino de Matemática no cenário atual e sobre a possibilidade de uso dessa metodologia em suas aulas. Esta terceira categoria constituiu-se de questões abertas, visto que ofereciam ao respondente liberdade de expressar sua opinião a respeito do que estava sendo perguntado (GIL, 2009).

As análises dos dados produzidos na pesquisa piloto revelaram que:

- Os doze professores formados há menos de 5 anos tiveram contato com a modelagem 
em sua formação na licenciatura, enquanto os doze professores com mais de 5 anos de prática profissional somente tiveram esse contato em cursos de formação continuada;

- Um terço dos participantes da pesquisa piloto ainda não tinham experiência em sala de aula, possuindo apenas experiência com aulas particulares;

- Dos vinte participantes que afirmaram ter experiência docente, treze destes professores atuavam na Educação Básica, principalmente no Ensino Fundamental II e no Ensino Médio. Dentre os demais, quatro atuam no Ensino Fundamental I e três no Ensino Superior;

- Com relação à escolha da profissão de professor de Matemática, um grupo de respondentes baseou suas respostas no fato de ter habilidade com a Matemática e outro grupo por ter apreço pela profissão. Fica claro que a decisão por optar por ser professor de Matemática foi influenciada por terem tido um ou mais professores que incentivaram essa escolha;

- As respostas sobre a pergunta "O que é Matemática?" revelaram que os professores participantes consideram a Matemática uma ciência, de maneira pura e dissociada dos acontecimentos do dia-a-dia, contudo capaz de promover a criticidade se for bem orientada para isso;

- Os professores revelaram que 0 insucesso dos alunos em Matemática pode ser influenciado por práticas pedagógicas docentes conservadoras que desconhecem metodologias alternativas de ensino, muitas vezes resultantes de uma formação profissional ainda precária nas licenciaturas;

- Percebemos, ao analisar os dados, a diversidade de opiniões quanto ao pertencimento da Modelagem Matemática à Educação Matemática, como metodologia de ensino, ambiente de aprendizagem etc., ou à Matemática Aplicada, como método de resolução de problemas por meio da linguagem Matemática. A partir dos dados produzidos no piloto, concluímos que ainda há uma forte tendência a relacionar o termo Modelagem Matemática à Matemática Aplicada;

- Embora os professores reconheçam a potencialidade da Modelagem Matemática como uma metodologia importante para desenvolver o conhecimento matemático dos estudantes, alegou-se que o cumprimento de um currículo extenso voltado para 
concursos e a falta de experiência em desenvolver projetos de modelagem faz com que o ensino sem essa metodologia ainda ocorra em suas salas de aula.

O estudo piloto nos possibilitou produzir dados e conhecer a opinião dos professores participantes. As respostas destes professores sinalizaram a importância de discutir, avaliar, sugerir e disseminar propostas que sirvam para implementação nas práticas escolares de propostas metodológicas com a Modelagem Matemática.

\subsection{Dados produzidos na Pesquisa Piloto}

Nesta seção detalhamos os principais dados produzidos a partir do formulário utilizado na pesquisa piloto. Estes dados serviram para orientar a pesquisa pós-piloto, que também produziu dados significativos, e nos auxiliaram em responder a pergunta de pesquisa, bem como a construir um produto educacional adequado e que, posteriormente, foi aprovado com mérito pela banca avaliadora da pesquisa.

Sobre a relação dos participantes com a Matemática, descobrimos a importância que dão ao reconhecer a Matemática como ciência e ferramenta com a qual podemos agir no mundo. Esse gosto pela Matemática é a razão apontada por parte dos participantes para a escolha pela profissão de professor de Matemática. Outra parte dos participantes justificou sua escolha pela vontade de ensinar.

Com relação ao ensino da Matemática, foi unânime entre os professores respondentes que este ensino ainda é falho. A esse respeito, assumem sua parcela de participação no insucesso, mas apontam a formação do professor como um dos fatores de maior relevância nessa discussão. São apontados ainda outros fatores, como falta de interesse dos estudantes, por exemplo. $O$ interessante é que os professores reconhecem a existência de pesquisas abordando vários temas relevantes para a melhoria do ensino de Matemática, mas que essas pesquisas não chegam de fato na sala de aula. Nesse sentido, um dos participantes, o P8, argumentou: "Vejo que existem muitos equívocos em relação a como e quais conteúdos devem ser apresentados. Noto também que temos muitas pesquisas que auxiliam na melhora deste ensino, porém ficam distante da prática" (FRANGO, 2019, p. 42).

Um outro dado relevante produzido sobre a relação dos participantes com a Modelagem Matemática apontou que aqueles com até dez anos de atuação e formação profissional, afirmam 
que tiveram contato com a Modelagem em sua formação inicial, enquanto aqueles com mais de dez anos de atuação e formação, afirmaram que tiveram contato com a Modelagem durante sua formação continuada e em participação em eventos acadêmicos.

Vale ressaltar que esse contato, afirmado pelos participantes, não se deu em uma disciplina específica sobre o tema. Em alguns casos se deu em disciplinas de prática pedagógica e em programas de iniciação à docência — onde era abordada como metodologia de ensino - e, outras vezes, como método da Matemática Aplicada. Nesse sentido, quando perguntados sobre como enxergam a Modelagem Matemática, a maioria relata que entendem como uma ferramenta para representar fenômenos em linguagem matemática, assim como na Matemática Aplicada. Uma pequena parte dos respondentes reconhecem a Modelagem como uma metodologia de ensino.

Quando inqueridos sobre a utilização da Modelagem Matemática em suas salas de aula, os professores participantes responderam, em sua maioria, positivamente, alegando ser esta uma forma de melhorar o ensino de Matemática. Ainda que tenham mostrado ser favoráveis a sua utilização, os participantes manifestaram insegurança pela falta de experiência, formativa e/ou prática. Os que alegaram não utilizar dessa metodologia em sua prática, responderam de forma negativa, justificaram referindo-se a: questão do currículo extenso; da falta de tempo para desenvolver tal metodologia; por não ter materiais de apoio; e pela falta de experiência em relação ao desenvolvimento desta metodologia.

Os dados produzidos no estudo piloto também "abriram nossos olhos" para o fato de que, embora a Modelagem Matemática seja falada, de forma breve, em contextos de formação, em muitos cursos de Matemática, ainda há um ruído muito grande. Um dado relevante obtido no estudo piloto é que tal ruído muitas vezes é provocado por ainda se considerar a Modelagem Matemática e Matemática Aplicada como sinônimos e que ambas se constituem da mesma forma.

Nesse sentido, esse "abrir de olhos" nos possibilitou também dar continuidade à pesquisa numa segunda fase (Pós-piloto), buscando desenvolver um programa disciplinar voltado à Modelagem Matemática e formação de professores que proporcionasse que a Modelagem pudesse fazer parte de suas práticas profissionais com seus estudantes. Nesta segunda fase da pesquisa, o objetivo era convidar outros sujeitos, distintos dos que participaram do estudo piloto. Estes novos participantes cursavam uma disciplina de mestrado profissional em Educação Matemática na UFJF e foram convidados a refletir, praticar ações e ter uma formação continuada 
em cenários de investigação (SKOVSMOSE, 2000) com a Modelagem.

Assim, ao final desse curso, buscamos ter dados produzidos que nos possibilitasse elaborar um produto educacional que propiciasse aos professores desenvolver práticas de Modelagem em diversos contextos e mediasse as práticas investigativas discentes. Este produto foi estruturado antes do início do estudo pós-piloto, contudo sofreu diversos ajustes ao longo do mesmo, recebendo contribuições dos participantes. Ou seja, ao longo desse curso de formação continuada as contribuições e críticas dos participantes às ações conduzidas pelos autores desse artigo foram sendo agregadas.

\subsection{Detalhando o contexto e os bastidores da Pesquisa Pós-Piloto}

A Pesquisa Pós-Piloto possibilitou-nos elaborar uma proposta de curso e sua concretização. Assim, surgiu a oportunidade de ser oferecida uma disciplina de Modelagem Matemática no Mestrado Profissional em Educação Matemática (UFJF), no primeiro semestre de 2018.

No encerramento do período de inscrições para a referida disciplina, contabilizaram-se 15 matriculados, dos quais 5 eram alunos regulares e 10 eram alunos especiais. Dos alunos especiais, 5 eram alunos da graduação, com experiência docente ou não, e os outros 5 eram licenciados em Matemática e estavam em exercício da profissão. Houve desistência de 4 alunos da graduação e a pesquisa pós-piloto contou com 11 participantes -1 aluno da graduação, licenciando, e 10 licenciados em Matemática).

A proposta dessa disciplina, ambiente das ações na pesquisa pós-piloto, foi apresentar a Modelagem como uma metodologia alternativa de ação educacional para a sala de aula de Matemática, além de possibilitar a participação, ações e depoimentos dos 11 participantes da pesquisa pós-piloto. Como constatado por meio dos dados produzidos na pesquisa piloto, existem carências curriculares quanto à Modelagem na formação inicial e continuada dos professores.

Desse modo, considerando o programa proposto, inicialmente, para o curso de Modelagem foram realizados doze encontros presenciais, março a junho de 2018, com duração de quatro horas cada, com início às 8 horas da manhã e término às 12 horas. Esses encontros não se restringiram ao ambiente da sala de aula. Houve também a ação dos participantes da disciplina, em momentos oportunos em outras dependências da universidade, com a realização 
de atividades práticas propícias aos cenários para investigação e modelagem de situaçõesproblema.

Os dados produzidos ao longo dessa disciplina de mestrado, cenário da pesquisa de campo pós-piloto, foram importantes para avaliar se o programa da disciplina caminhava no sentido de proporcionar uma formação inicial/continuada com relação à Modelagem. Esses dados possibilitaram a gênese do produto educacional que busca orientar os (futuros) professores a estarem sempre se atualizando e ousando criar cenários para investigação com Modelagem em suas salas de aula.

A dinâmica dos encontros registrados em diários nossos, pesquisadores autores deste artigo, seguia um roteiro. Os participantes liam textos e artigos sugeridos, previamente, refletiam sobre suas leituras, além de serem sugeridas leituras adicionais que, tanto os professores que ministravam a disciplina, autores desse artigo, quanto os participantes davam suas contribuições na primeira parte dos doze encontros realizados.

No primeiro encontro foi proposta uma atividade de modelagem envolvendo a queda de um talude (barranco) num instituto da universidade. Os professores participantes da disciplina deveriam modelar o problema do barranco, ao longo do semestre, buscando investigar o quanto de terra havia desmoronado e investigar como foi feita a obra de recomposição do barranco com uma estrutura de degraus com sacos de brita e cimento. Esta proposta de investigação e modelagem de uma situação prática era inédita à epoca e ainda não havia ainda sido explorada em outra disciplina ou por outros professores.

Nos primeiros encontros notamos que os participantes falavam, brevemente, sobre suas ações de investigação e modelagem do desmoronamento do barranco, contudo, mais adiante, passados sete encontros formativos, os professores-colaboradores começaram a manifestar queixas com relação ao acompanhamento da atividade de Modelagem por parte dos professores formadores que ministravam a disciplina de Modelagem e autores desse artigo.

De acordo com os participantes, eles estavam sentindo dificuldades em estruturar os modelos, mesmo após discussões na disciplina, leituras de artigos e pesquisas. A esse respeito, Vertuan, Borssoi e Almeida (2012) argumentam que

dentre muitos aspectos que um ambiente de Modelagem proporciona, ocorre a externalização de modelos mentais dos alunos, que são artefatos cognitivos importantes a partir dos quais o professor pode agir no sentido de realizar mediação 
no processo de significação/ ressignificação dos alunos. (p. 5)

Assim, os participantes sugeriram que alguns encontros, ou uma parte de cada encontro, deveriam ser dedicados ao problema do talude. Optamos por reservar a segunda parte dos encontros formativos na disciplina, após a pausa para o lanche, para discussões do andamento da atividade proposta de Modelagem do desmoronamento do barranco. As solicitações dos participantes nos auxiliaram muito a compreender que a nossa proposta de curso precisava de ajustes finos e necessários.

Esses ajustes foram adequados no produto educacional buscando oferecer uma formação teórica em Modelagem na sala de aula para que o professor, que opte por utilizar essa metodologia em sua prática, sinta-se mais empoderado para fazer os convites aos alunos para investigar temas e que saiba ir mediando as ações investigativas dos estudantes ao longo do processo.

A solução do problema do talude foi feita por grupos formados logo no início da disciplina formativa. Após leituras, discussões e idas e vindas ao local onde ficava o barranco, os grupos de professores participantes da disciplina apresentou um artigo com seu percurso epistemológico e metodológico. Nesse artigo, produzido por cada grupo, foram descritas suas ações, estratégias e resoluções utilizando seus conhecimentos matemáticos e tecnológicos - softwares como 0 GeoGebra foram utilizados - para modelar o problema do barranco. Na versão final do texto dissertativo, nos anexos, apresentamos todos os artigos com suas respectivas trajetórias e soluções para o problema de modelagem do talude.

\subsection{Dados produzidos na Pesquisa Pós-Piloto}

Os dados da fase pós-piloto foram registrados em um diário de campo, em gravações de áudio, autorizadas pelos participantes desta etapa da pesquisa, e por meio de documentos resumos, apresentações, redações e avaliações feitas pelos participantes.

No diário de campo foram registrados comentários, falas, debates e momentos que consideramos relevantes para nossa pesquisa. Dentre estes, destacamos as solicitações periódicas dos participantes dessa fase da pesquisa para que fosse mais explorado a prática de Modelagem Matemática durante a formação, além das discussões teóricas. Os participantes apontaram que dentre os vários fatores que provocava a ausência de ações didáticas de Modelagem Matemática nas suas salas de aula se devia à insegurança em realizá-las com êxito 
e experiência.

Outro dado importante descoberto nessa fase foi 0 referente à oportunidade de experienciar a Modelagem Matemática na posição do aluno e praticá-la. Na formação, propusemos uma atividade de Modelagem Matemática relacionada à queda de um talude (barranco) em um dos departamentos do campus da UFJF. Assim, durante os encontros formativos, os participantes apontaram que foi possível perceber a importância da mediação do professor para a realização da tarefa. Relataram ainda as dificuldades e potencialidades da realização de atividades em grupo e fora da sala de aula e, dessa forma, pensar suas práticas com Modelagem de forma a agir com mais eficiência diante de situações que possam surgir durante a realização da atividade investigativa.

Um conjunto precioso de dados foi obtido por meio de uma avaliação aplicada na metade do curso. Por meio da análise documental dessas avaliações, inferimos a forte influência da perspectiva sociocrítica nas concepções teóricas dos participantes, ao analisarmos suas respostas. Ao final do curso, os participantes produziram artigos a partir da sua experiência com a atividade sobre o talude (barranco). Analisando-os, pudemos perceber que eles mostraram como todos os assuntos abordados durante o curso dialogaram e se entrelaçaram durante a composição do texto. Foi possível perceber que as discussões propostas foram pertinentes para que cada participante construísse a sua percepção sobre a Modelagem Matemática e sua utilização e potencialidade para o ensino e aprendizagem de Matemática.

Ao final do curso ministrado na disciplina do mestrado, etapa pós-piloto, realizamos uma avaliação. Nesta, os participantes expressaram sua opinião quanto ao que consideraram bom no curso e apontaram o que poderia ter sido feito. O curso recebeu aprovação por parte dos participantes, que afirmaram querer um curso com carga horária maior para que pudessem ser abordados mais assuntos e apontaram a necessidade de mais atividades práticas, tanto de prática docente quanto discente (como na atividade do talude).

\section{Detalhando a gênese do Produto Educacional}

A Modelagem Matemática pode vir a se tornar uma metodologia mais presente nas ações educacionais de sala de aula, mas ainda é pouco conhecida por muitos professores de Matemática. Conforme destacado em Frango (2019), professores sentem a necessidade de conhecer mais a respeito desta proposta, e acreditam que práticas envolvendo a Investigação e a 
Modelagem de situações-problema deveriam ser exploradas nos cursos de formação inicial e continuada de Matemática.

Nossa ideia inicial foi desenvolver um material de apoio para os professores formadores, visto que, durante o percurso de realização das ações de nossa pesquisa, não foi encontrado nenhum material como o que apresentamos em nosso Produto Educacional. A esse respeito nos foram feitos alguns questionamentos sobre existir interesse por parte dos formadores em utilizar o material para basear seus cursos de Modelagem Matemática. Isso poderia render uma nova pesquisa, mas o fato é que nos possibilitou reflexões a respeito da utilização do material.

Observamos na prática diária da profissão docente que o professor, muitas vezes, e por muitos motivos, torna-se autodidata, buscando novos métodos e novas formas de aprimorar seu desempenho. Com isso, percebemos que nosso produto educacional poderia se constituir num guia de autoformação. Por meio desse guia o professor poderia conhecer e refletir a respeito da Modelagem, sua origem, características, ideias que deram certo, ideias que ainda não deram certo, e, assim, constituir e desenvolver sua própria prática, construindo uma prática autônoma.

Desenvolvemos, assim, um material que possibilitasse ao professor de Matemática em formação, explorar de forma abrangente e atemporal os temas em diversas perspectivas, considerando os vários níveis de escolaridade e modalidades de ensino com a participação efetiva e atuante dos estudantes e fazendo as suas adaptações aos contextos dos estudantes.

É importante destacar que, durante a disciplina de Modelagem Matemática no mestrado profissional, o produto foi sendo (re)ajustado a cada semana observando-se a participação dos professores que estavam na disciplina. Como pesquisadores percebemos que cada bloco do produto que continha os encontros e módulos deveriam ser regulados, a partir dos diálogos que ocorriam na disciplina, conforme os participantes desenvolviam as leituras e as tarefas do curso.

Destarte, o nosso produto educacional se constituiu de um manual dividido em dois blocos. O primeiro bloco apresenta discussões teóricas sobre Modelagem e Investigação na sala de aula de Matemática e em contextos não-escolares. Já o segundo bloco apresenta propostas de práticas de Modelagem e Investigação. Cada bloco do produto organiza-se em módulos temáticos que, por sua vez, se subdividem em encontros, o que equivaleria a um encontro formativo presencial. No total, o guia apresenta dois blocos com onze módulos e trinta encontros.

Como revela a Figura 1, a seguir, os encontros foram estruturados em uma breve introdução sobre o assunto abordado e segue-se de um subtítulo nomeado Por dentro do assunto, 
que fala da importância daquele tema na formação proposta. Na sequência, temos o subtítulo Trocando ideias, que propõe reflexões a respeito do tema. Os dois últimos subtítulos são Links interessantes e Sugestões de leitura.

Nesses espaços trazemos links que direcionam os professores para sites com propostas de atividades, materiais, compartilhamento de experiências e são indicadas referências diversas sobre o tema abordado no "encontro" para que o professor em formação possa se aprofundar mais no assunto e criar seus materiais pedagógicos adequados a seu contexto escolar e social.

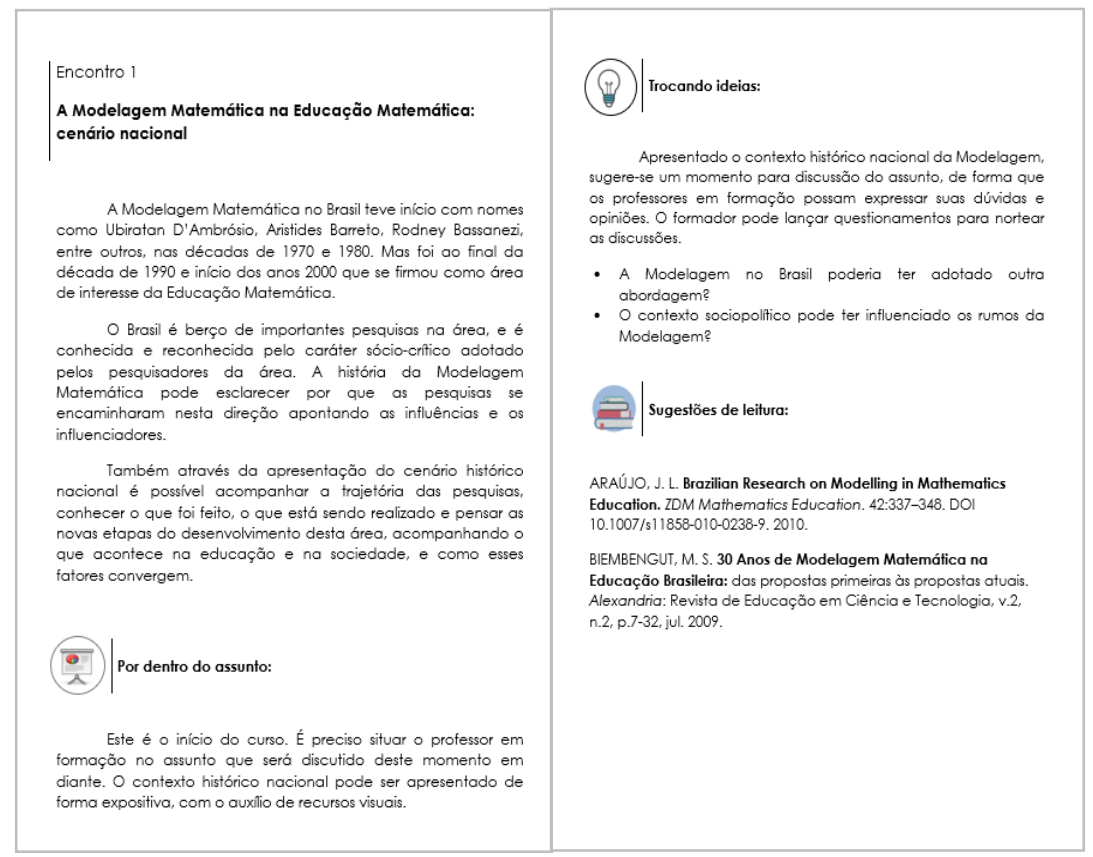

Figura 1: Página do Encontro 1 - Produto Educacional (Elaboração dos Autores)

Embora tenha sido feito buscando-se cumprir todas as orientações metodológicas explicitadas pela Coordenadoria de Aperfeiçoamento de Pessoal de Nível Superior (CAPES), 0 produto educacional em questão tem suas limitações e pode ser ampliado e melhorado por futuros professores-pesquisadores. Destacamos que, embora haja uma versão disponível para acesso de toda a comunidade acadêmica ${ }^{1}$, o produto está aberto a sofrer críticas dos professores e adaptações, de modo que ele possa ser ampliado e adaptado para a diversidade de contextos escolares que existem em nosso país.

\footnotetext{
1 Disponível em www.uff.f.br/mestradoedumat
} 


\section{Considerações}

$\mathrm{Na}$ pesquisa apresentada neste artigo, o professor participante assumiu o papel de protagonista em sua formação. Assim também se espera que ocorra em outras formações, baseadas ou não no guia formativo desenvolvido nesta pesquisa. Vale ressaltar que toda formação deve se basear nos objetivos almejados. Que professores pretendemos formar? Para quê? De que forma? Nesta pesquisa intencionamos (trans)formar um professor crítico, criativo, para trabalhar com/por meio da Modelagem, de forma que ele expresse suas expectativas e receios, possibilitando que a formação seja a mais adequada ao público que atende.

Assim, não esperamos que este guia formativo seja a solução definitiva para as questões que envolvem a formação de professores em Modelagem, muito menos que transforme, instantaneamente, as salas de aula de Matemática, dos diversos níveis e modalidades de ensino. Esperamos que esse material seja uma alternativa metodológica para que em conjunto e de forma colaborativa, professores formadores e professores em formação adaptem-no ao seu contexto e às necessidades de aprendizagem de seus estudantes.

Assim, defendemos a valência da Modelagem como "um ambiente de aprendizagem no qual os alunos são convidados a indagar e/ou investigar, por meio da matemática, situações oriundas de outras áreas da realidade" (BARBOSA, 2001, p. 31), como forma de contestar e transformar a realidade do ensino e da aprendizagem de Matemática.

Enfatizamos que a pesquisa piloto nos permitiu conhecer a relação dos professores que ensinam Matemática com a Modelagem em sua formação, inicial e/ou continuada. Reiteramos ainda as contribuições de um curso de Modelagem Matemática para a formação e atuação de professores de Matemática (Pesquisa Pós-piloto). Este curso que nos possibilitou tecer o produto educacional e, por meio das críticas e sugestões dos participantes do curso, revelar o potencial desta proposta e da sua possível utilização nas salas de aula de Matemática, como uma proposta de cenários para investigação que promova a criticidade no processo de ensino e de aprendizagem.

Para o desenvolvimento de ações de investigação de modelagem na sala de aula de Matemática, inferimos, é preciso que seja estabelecida uma relação dialógica entre professor e alunos de forma que estes se integrem colaborativamente nesse processo de construção do conhecimento matemático. Neste contexto, o professor deve desempenhar o papel de mediador das ações investigativas dos estudantes, com planejamento e utilização de materiais como os 
produtos educacionais que têm sido ofertados, trabalhando no sentido de intervir para que os alunos desenvolvam autonomia perante suas ações diante do objeto investigado.

Pretendemos ainda disponibilizar tanto a dissertação quanto o produto educacional em formato de e-book e na versão impressa. Esta ação busca possibilitar que essa pesquisa chegue a todos os interessados e, principalmente, aos professores da Educação Básica, sendo 0 distanciamento entre escola e universidade, pesquisador e professores, uma das queixas apresentadas na primeira fase desta pesquisa.

\section{Agradecimentos}

Como educadores matemáticos engajados em práticas de educação crítica e libertadora que possibilite, como Paulo Freire nos ensinou, a emancipação dos sujeitos participantes do processo educacional, gostaríamos de agradecer aos participantes dos estudos dessa pesquisa todas as contribuições dadas ao longo da pesquisa. Em especial, também agradecemos ao educador matemático e pesquisador Neil da Rocha Canedo Júnior pela leitura das versões desse artigo, bem como pelas sugestões dadas para que o texto ficasse didático, útil e incentivassem os professores e futuros professores a praticarem a Modelagem em suas salas de aula como sempre foi feito pelo Neil. Muitas de nossas ações como pesquisadores e educadores matemáticos foram inspiradas nas práticas do Neil em suas aulas na educação básica em escolas de periferia em Juiz de Fora (MG).

Por fim dedicamos esse artigo a dois educadores matemáticos, Romulo Campos Lins e Ole Skovsmose que têm contribuições imprescindíveis para a formação de professores e que têm nos inspirado em nossas ações como educadores matemáticos.

\section{Referências}

ALRØ, Helle; SKOVSMOSE, Ole. Diálogo e aprendizagem em Educação Matemática. Tradução de Orlando de Andrade Figueiredo. Belo Horizonte: Autêntica, 2010.

ANDRÉ, Marli Eliza Dalmazo Afonso de. Estudo de caso: seu potencial na Educação. Cadernos de Pesquisa, São Paulo, v. 49, 1984.

ARAÚJO, Jussara de Loiola. Brazilian research on modeling in Mathematics Education. ZDM Mathematics Education, v. 42, n. 3-4, p. 337-348, jun. 2010. 
ARAÚJO, Jussara de Loiola. Ser crítico em projetos de modelagem em uma perspectiva crítica de Educação Matemática. Bolema, Rio Claro, v. 26, n. 43, p. 839-859, ago. 2012.

ASSIS, Leonardo de. Modelagem Matemática na formação de professores: algumas contribuições. 2013. 140f. Dissertação (Mestrado em Educação Matemática) - Instituto de Ciências Exatas e Biológicas. Universidade Federal de Ouro Preto. Ouro Preto.

BARBOSA, Jonei Cerqueira. Modelagem Matemática: concepções e experiências de futuros professores. 2001. 253f. Tese (Doutorado em Educação Matemática) — Instituto de Geociências e Ciências Exatas. Universidade Estadual Paulista. Rio Claro.

BARBOSA, Jonei Cerqueira. Sobre a pesquisa em Modelagem Matemática no Brasil. In: CONFERÊNCIA NACIONAL SOBRE MODELAGEM NA EDUCAÇÃO MATEMÁTICA, 5, 2007, Ouro Preto. Anais da V CNMEM. Ouro Preto: UFOP, 2007, p. 82-103.

BASSANEZI, Rodney Carlos. Ensino-Aprendizagem com Modelagem Matemática. São Paulo, 2004.

BIEMBENGUT, Maria Salett. 30 anos de Modelagem Matemática na educação brasileira: das propostas primeiras às propostas atuais. Alexandria, Florianópolis, v. 2, n. 2, p. 7-32, jul. 2009.

BIEMBENGUT, Maria Salett. Modelagem Matemática \& implicações no ensino-aprendizagem de Matemática. 2. ed. Blumenau: EdFURB, 2004.

BORBA, Marcelo de Carvalho; VILLARREAL, Mônica Ester; SOARES, Débora da Silva. Modeling using data available on the internet. In: HIRSCH, Christian R.; McDUFFIE, Amy Roth. Mathematical Modeling and Modeling Mathematics. New York: NCTM, 2016, p. 143-152.

BORSSOI, Adriana Helena; SILVA, Karina Alessandra Pessoa da. Mídias educacionais em um ambiente virtual de ensino e aprendizagem: ampliando possibilidades para 0 trabalho colaborativo. Contexto \& Educação, ljuí, v. 32, n. 103, p. 248-274, set./dez. 2017.

BRASIL. Ministério da Educação. Secretaria de Educação Básica. Base Nacional Comum Curricular. Educação Infantil e Ensino Fundamental. Brasília: MEC/SEB, 2017.

BURAK, Dionisio. Modelagem matemática: ações e interações no processo de ensinoaprendizagem. 1992. Tese (Doutorado em Educação) — Faculdade de Educação. Universidade Estadual de Campinas. Campinas.

CANEDO JR., Neli da Rocha. A modelagem como uma "atividade" de "seres-humanos-commídias". 2014. 238f. Dissertação (Mestrado em Educação Matemática) — Instituto de Ciências Exatas. Universidade Federal de Juiz de Fora. Juiz de Fora.

D’AMBRÓSIO, Ubiratan. Educação Matemática: da teoria à prática. 23. ed. Campinas: Papirus, 2012.

FIORENTINI, Dario; LORENZATO, Sergio. Investigação em Educação Matemática: percursos teóricos e metodológicos. Campinas: Autores Associados, 2006.

FONSECA, João José Saraiva da. Metodologia da pesquisa científica. Fortaleza: UEC, 2002. 
FRANGO, Edyenis Rodrigues. As contribuições de um curso de formação em Modelagem Matemática para o desenvolvimento de um guia formativo na perspectiva dos professores participantes. 2019. 181f. Dissertação (Mestrado em Educação Matemática) - Instituto de Ciências Exatas. Universidade Federal de Juiz de Fora. Juiz de Fora.

GERHARDT, Engel Gerhardt; SILVEIRA, Denise Tolfo. (Org.). Métodos de pesquisa. Porto Alegre: EdUFRGS, 2009.

GIL, Antonio Carlos. Como elaborar projetos de pesquisa. 4. ed. São Paulo: Atlas, 2009.

GOLDENBERG, Mirian. A arte de pesquisar. Rio de Janeiro: Record, 1997.

LOPES, Celi Espassadin; D'AMBROSIO, Beatriz Silva. Professional development shaping teacher agency and creative insubordination. Ciência \& Educação. Bauru, v. 22, n. 4, p. 1085-1095, out./dez. 2016.

MACHADO, Nilson José. Formação do Professor de Matemática: currículos, disciplinas, competências, ideias fundamentais. In: CARVALHO, Ana Maria Pessoa de. (Org.) Formação continuada de professores: uma releitura das áreas do cotidiano. São Paulo: Cencage, 2017, p. 37-68.

MALHEIROS, Ana Paula dos Santos. Pesquisas em Modelagem Matemática e diferentes tendências em Educação e Educação Matemática. Bolema, Rio Claro, v. 26, n, 43, p. 89-110, ago. 2012.

MINAYO, Maria Cecília de Souza. (Org.). Pesquisa social: teoria, método e criatividade. Petrópolis: Vozes, 2001.

MUTTI, Gabriele de Sousa Lins. Práticas pedagógicas de professores da educação matemática num contexto de formação continuada em Modelagem Matemática na Educação Matemática. 2016. 236 f. Dissertação (Mestrado em Ensino) - Centro de Educação, Letras e Saúde. Universidade Estadual do Oeste do Paraná. Foz do Iguaçu.

NÓVOA, Antonio. Para una formación de profesores construida dentro de la profesión. Revista de Educación, n. 350, p. 203-218, set./dez. 2009.

OLIVEIRA, Andreia Maria Pereira de. Modelagem matemática e as tensões nos discursos dos professores. 2010. 199f. Tese (Doutorado em Ensino, Filosofia e História das Ciências) Universidade Federal da Bahia. Universidade Estadual de Feira de Santana. Salvador.

OLIVEIRA, Wellington Piveta. Modelagem Matemática nas licenciaturas em Matemática das universidades estaduais do Paraná. 2016. 155f. Dissertação (Mestrado em Educação) - Centro de Educação Comunicação e Artes. Universidade Estadual do Oeste do Paraná. Cascavel.

ROSA, Milton. Currículo e Matemática: algumas considerações na perspectiva etnomatemática. Plures Humanidades, Ribeirão Preto, n. 6, v. 6, p. 81-96, 2005.

ROSA, Milton; OREY, Daniel Clark. Etnomodelagem: a arte de traduzir práticas matemática locais. São Paulo: Livraria da Física, 2017. 
SILVEIRA, Everaldo. Modelagem Matemática em Educação no Brasil: entendendo o universo de teses e dissertações. 2007. 208f. Dissertação (Mestrado em Educação) - Setor de Educação. Universidade Federal do Paraná. Curitiba.

SILVEIRA, Everaldo; CALDEIRA, Ademir Donizeti. Modelagem na sala de aula: resistências e obstáculos. Bolema, Rio Claro, v. 26, n. 43, p. 1021-1047, ago. 2012.

SKOVSMOSE, Ole. Educação Matemática Crítica: a questão da democracia. Campinas: Papirus, 2001.

SKOVSMOSE, Ole. Cenários para investigação. Tradução de Jonei Cerqueira Barbosa. Bolema, Rio Claro, SP, v. 13, n. 14, p. 66-91, 2000.

TAMBARUSSI, Carla Melli. A formação de professores em Modelagem Matemática: considerações a partir de professores egressos do Programa de Desenvolvimento Educacional do Paraná - PDE. 2015. 179f. Dissertação (Mestrado em Educação) - Centro de Educação, Comunicação e Artes. Universidade Estadual do Oeste do Paraná. Cascavel.

TARDIF, Maurice. Saberes docentes e formação profissional. Tradução de Francisco Pereira. 4. ed. Rio de Janeiro: Vozes, 2010.

THIOLLENT, Michel. Metodologia da pesquisa-ação. São Paulo: Cortez Editora, 2005.

TORTOLA, Emerson. Configurações de Modelagem Matemática nos Anos Iniciais do Ensino Fundamental. 2016. 304f. Tese (Doutorado em Ensino de Ciências e Educação Matemática) Centro de Ciências Exatas. Universidade Estadual de Londrina. Londrina.

VERTUAN, Rodolfo Eduardo; BORSSOI, Adriana Helena; ALMEIDA, Lourdes Maria Werle de. 0 papel da mediação e da intencionalidade em atividades de Modelagem Matemática. In: SEMINÁRIO INTERNACIONAL DE PESQUISA EM EDUCAÇÃO MATEMÁTICA, 5, 2012, Petrópolis. Anais do V SIPEM. Petrópolis: SBEM, 2012, p. 1-19.

YIN, Robert K. Estudo de caso: planejamento e métodos. Tradução de Daniel Grassi. Porto Alegre: Bookman, 2001. 